\title{
CLIMATE ADAPTABILITY IN THE HEJAZI TRADITIONAL ARCHITECTURE
}

\author{
MOHAMMED BAGADER \\ PhD Candidate in Architecture - The University of Manchester the UK.
}

\begin{abstract}
All types of architecture worldwide are seeking to cope, adapt and interact with the surrounding environment, whether that is with climate, topography or any other kind of environmental challenges. Climate adaptability plays a significant role in formulating any architecture in terms of the buildings' heights, shapes, materials and so on. The traditional architecture in the Hejaz region, which is considered as one of the Islamic architecture types, is an interesting example to show how the inhabitants have adapted with climate, a sustainable architecture the still intact until the present day. This paper presents the traditional Hejazi architectural techniques in dealing with climate adaptability by describing the various architectural principles, materials and components such as the rawashan and the courtyard. Traditional methods and techniques will be explored through illustrating different architectural features. Finally, the discussion will outline the basic principles that should be implemented in the design of buildings in order to promote environmental-friendly and sustainable architecture.
\end{abstract}

Keywords: climate adaptability, Hejaz region, traditional architecture.

\section{INTRODUCTION}

Changing climate is considered a major challenge to deal with, especially in countries that have obvious climatic changes seasonally such as the UK [1]. On the other hand, there are some countries that do not suffer from climatic changes, like the Hejaz region, due to the similarity among the four seasons annually [2]. In some countries they are facing less problems when compared with the other countries regarding climate. The Hejaz region will be the focus of this study. In this region, the inhabitants suffer from a hot-dry or hot-humid weather, which must be addressed and dealt with to make the life of its inhabitants more tolerable and comfortable [3]. The hot weather has been documented for a long time. The architectural heritage of Hejaz is an excellent example for local response to cope with such challenge.

The Hejaz region, though has a glorious and beautiful architectural heritage, has proved through the ages to be able to cope with climatic challenges and has proved to reflect the local aesthetic and social and cultural norms, and recent lifestyles make many of its aspects absolute. Even the traditional architecture methods have become costly and unpractical to choose. However, as the paper will show, many of these new innovations, though provided quick, useful solutions, in the meantime produced new problems and were hazardous.

The main objective of this paper is to understand the climatic changes that the Hejazi region faces, in order to understand the traditional solutions of adaption and coping with climate. The Hejaz region witnessed several types of architectural solutions regarding climate issues; the paper will focus on the traditional school of architecture, attempting to define the advantages and disadvantages. Major cities located in the Hejaz region will be discussed and investigated in many aspects, climatically and architecturally. The paper will analyse different building materials and techniques used in architecture to gain an understanding of the traditional methods implemented in this region. 


\section{THE HEJAZ REGION}

'Hejaz' literally means barrier; it is a huge geographical area that intersects between the coastal area of Tehama and the plateau of Nejd in the Arabian Peninsula (Fig. 1). The Hejaz region stretches along the Red Sea, with a series of mountains called Alsarwat. However, we will focus mainly on the urban centres and their built environment. Hejaz is considered as a religious region due to the presence of two holy cities for Muslims (Makkah and Al-Medina). This chapter will highlight the changes in the climate in the Hejaz region during the last five decades.

\subsection{The climate in the Hejaz region}

The Hejaz region is a part of the global system [5], so it has been affected by the global changes with the rise of average temperature from approximately $23^{\circ} \mathrm{C}$ to more than approximately $35^{\circ} \mathrm{C}$ (in summers) [2]. However, all documented information have shown that the climate was dry or humid and hot most of the year in this region except for Al-Medina and Taif, which have another situation (cool and cold in winter season) due to the different topographical characteristics.

The Saudi Presidency of Meteorology and Environment statistics report illustrates that the average temperature in the Hejaz region have been rising in the last 30 years rapidly [2].

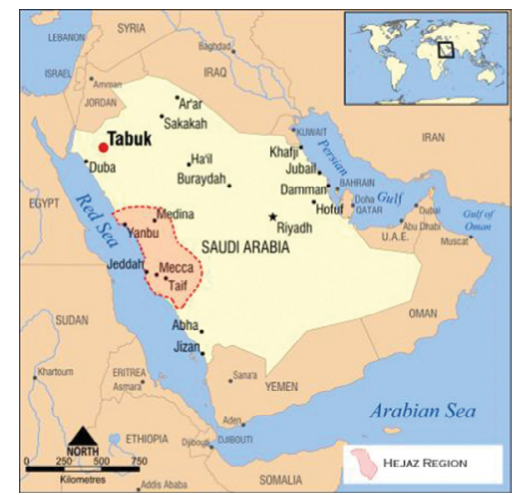

Figure 1: The location of the Hejaz region in Saudi Arabia [4].

\begin{tabular}{|c|c|c|c|c|c|c|c|c|c|c|c|c|}
\hline City & Jan & Feb & Mar & Apr & May & Jun & Jul & Aug & Sep & Oct & Nov & Dec \\
\hline \multirow{2}{*}{ Jedalh } & 23.5 & 23.6 & 25.3 & 27.5 & 29.8 & 31.3 & 31.9 & 31.9 & 31.1 & 29.5 & 27.2 & 24.8 \\
\hline & 19.9 & 29.1 & 28.2 & 33.2 & 35.2 & 36.2 & 37.0 & 37.9 & 36.3 & 35.4 & 33.1 & 30.6 \\
\hline \multirow{2}{*}{ Al-Medina } & 17.7 & 20.0 & 23.3 & 27.3 & 31.3 & 34.3 & 34.1 & 34.3 & 33.5 & 28.9 & 23.3 & 19.3 \\
\hline & 18.1 & 21.0 & 22.3 & 27.2 & 33.2 & 36.1 & 36.3 & 35.1 & 35.2 & 29.0 & 24.0 & 20.0 \\
\hline \multirow{2}{*}{ Makkah } & 23.0 & 24.0 & 27.0 & 31.0 & 34.0 & 35.0 & 35.0 & 35.0 & 35.0 & 32.0 & 28.0 & 25.0 \\
\hline & 24.2 & 25.6 & 28.1 & 33.0 & 36.7 & 36.9 & 37.4 & 39.1 & 35.0 & 31.2 & 27.1 & 26.4 \\
\hline \multirow{2}{*}{ Taif } & 15.0 & 15.7 & 19.0 & 21.7 & 24.7 & 27.1 & 27.7 & 28.3 & 26.6 & 22.4 & 18.0 & 15.8 \\
\hline & 15.8 & 16.0 & 20.4 & 22.5 & 26.3 & 28.4 & 29.0 & 29.0 & 24.2 & 22.4 & 17.3 & 15.8 \\
\hline \multirow{2}{*}{ Yanbu } & 19.8 & 20.3 & 23.2 & 26.4 & 29.6 & 31.3 & 31.6 & 31.6 & 31.1 & 28.9 & 24.8 & 21.6 \\
\hline & 18.9 & 19.4 & 22.1 & 26.7 & 29.1 & 32.1 & 32.1 & 32.4 & 32.5 & 30.1 & 28.4 & 24. \\
\hline
\end{tabular}

Figure 2: Average temperatures in the major cities of the Hejaz region 1980-2009 [2]. 
Figure 2 shows a huge increase of temperature, which occurred in the period between 1980 and 2009. For instance, in the summer of 1980 the average temperature in Jeddah was $31^{\circ} \mathrm{C}$, and in the winter was $25^{\circ} \mathrm{C}$. On the other hand, the average temperature of the summer of Jeddah in 2009 was $42^{\circ} \mathrm{C}$, and the winter was $30^{\circ} \mathrm{C}$. After analysing the climatic records, it has been very clear that the average temperatures between summers and winters in the region in the last 30 years have risen approximately by an average of $10^{\circ} \mathrm{C}$ and more. Furthermore, the rise in the average temperature has spread to almost the whole region of Hejaz.

The major natural reasons are due to the presence of desert and mountains in the surroundings, aridity, poor vegetation, lack of water due to low rainfall, and the topographical location of these towns. Rainfall was very low in the Hejaz region [6]. The weather in Makkah, for instance, is very dry and hot mainly because it is located in a dry mountainous valley, surrounded by deserts and high mountains. Al-Medina is located on a volcanic lava valley and surrounded by desert in one side and mountains in the other side. The city of Taif is located in a high mountain area and enjoys some rainfall during the year, which is why it has somewhat cooler weather. Both Jeddah and Yanbu are located by the coast of the Red Sea; their weather is hot and humid. Jeddah is located on a flat valley with complex topography of intersected flood paths. Yanbu is by the seacoast and surrounded by mountains. The weather is hot and humid most of the year.

However, according to K. Talib's book Shelter in Saudi Arabia, the climatic zones in Saudi Arabia range from hot-dry, hot-humid, composite to upland climatic characteristics [3]. In order to understand the impact of climate upon various buildings it is important to define the different climatic zones, which occur in the Hejaz region. In the Hejaz region, generally, there exist two climatic zones: hot-dry and hot-humid (see Fig. 3).

\subsubsection{Characteristics of the hot-dry climatic zone}

The temperature of the hot-dry climatic zone reaches an average maximum of $40^{\circ} \mathrm{C}$ daily during May to September and the highest temperature of $43^{\circ} \mathrm{C}$ during July. The highest average relative humidity reaches up to $50 \%$ during November to February. Therefore, the colder temperatures result in higher rainfall and humidity during the year. The annual average rainfall in the hot-dry climate reaches $59 \mathrm{~mm}$, which is commonly during the months

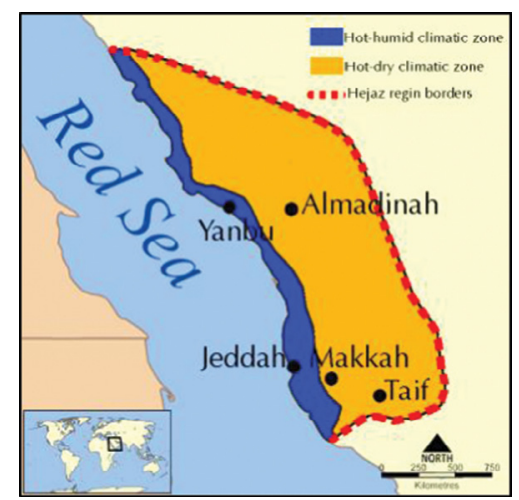

Figure 3: The climatic zones in the Hejaz region: hot-dry and hot-humid [7]. 
of December to May. However, the highest average rainfall of $21 \mathrm{~mm}$ can be found towards March and April. The hot-humid climatic zone can be found in the coastal area in the west of Saudi Arabia such as Jeddah and Yanbu [2, 3].

\subsubsection{Characteristics of the hot-humid climatic zone}

The temperature of the hot-humid climatic zone reaches an average maximum temperature of $42^{\circ} \mathrm{C}$ during the summer months of May, June, July and August. During the winter months the average daily temperature reaches around $15^{\circ} \mathrm{C}$. The average daily rainfall in the hot-humid zone varies around $12 \mathrm{~mm}$, however; the rainfall activity can be irregular during the months of October and April. The average relative humidity can rise up to $75 \%-80 \%$ throughout the year, especially around the coastline. The hot-dry climatic zone can be found towards inland where cities such as Makkah and Al-Medina are located $[2,3]$.

In summary both the hot-dry and hot-humid climatic zones share significant high levels of heat during most of the year. A higher percentage of humidity can be found in the cities located in the coastal areas near the Red Sea. The average rainfalls in both climatic zones are extremely irregular and have a low average daily rainfall during all seasons in the year. Both climatic zones have had considerable impact upon the buildings' designs, materials and urban fabric.

\section{THE TRADITIONAL HEJAZ ARCHITECTURE AND ITS WAY TO ADAPT WITH THE CLIMATE}

\subsection{Traditional house of Hejaz}

Islam has had a significant impact on the houses of Hejaz in many sectors, not just the constructions but also the characteristics [8]. The question of privacy and modesty, respecting the neighbour's preference to have sunlight, and also air circulation, and many other aspects have to be taken into account [9]. As Rapaport describes,

A house is an institution, not just a structure, created for a complex set of purposes. Because building a house is a cultural phenomenon, its forms and organization are greatly influenced by cultural milieu. [10]

This statement is a near-accurate explanation for traditional Hejazi houses, which have been designed and built to fit and suit the environmental needs, which reflect the Islamic vital norms and principles such as privacy and modesty. Furthermore, Hejaz houses usually consist of 3-4 floors and some times more than 5 floors; they are tall and vertical houses to fulfil these laws and to provide the largest possibility for the ventilation of air.

However, millions of pilgrims come annually to the holy cities (Makkah and Al-Medina) throughout the Islamic history (for 1,432 years); some of them settle down here and become citizens [11]. Therefore, the social structure of Hejaz is made of different ethnic backgrounds, and that has been apparent in traditional houses. Rawashans (the wooden balconies), for instance, originally came from the Egyptian tradition (the Mamluk empire in Egypt) [11]. To sum up, the interesting thing about Hejaz is that the region has always kept the traditional building methods and the cultural structure rules with regard to designing houses in this region (Fig. 4). 


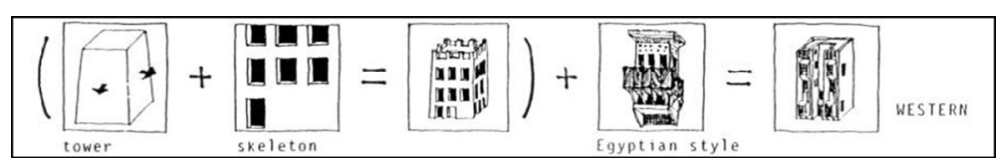

Figure 4: The basic equation showing the influence of Egyptian style on the traditional architecture of Jeddah [12].

\subsection{Solutions for Hejazi traditional architecture to adapt with climate}

As mentioned earlier the traditional Hejaz architecture responded and interacted with the surrounding environment in order to cope with it. The way of interaction in Hejazi traditional architecture with the surrounding environment was primitive and local. The two main climatic zones had huge impacts on Hejaz architecture, which will be explained and compared. The traditional architecture in Hejaz did not avoid climate challenges but in fact coped with it. This section will list the traditional methods of adapting with climate without harming the local environment, in terms of materials used, natural ventilation system, natural illumination, shade and shadow and some other elements used to decrease the impact of the hot temperature.

\subsubsection{The architectural form and structure}

The typical of Hejazi traditional houses was the vertical distribution (3-7 floors) of rooms around a stairwell in order to provide natural ventilation to all rooms [9]. At the ground level, there were usually two entrances to the house, one for the male visitors, and the other for the family. Some manner of connection between the two entrances was provided, and this formed a kind of central circulation axis. This axis sometimes took the form of a winding narrow corridor; on other occasions, it passed through a series of central room-like spaces. The staircase, at the ground floor, was mostly situated at the back of the house near the rear entrance [13].

A simple response to local climate and prevailing breeze was the governing factor in the allocation of living rooms. The builders took much advantage of the north and the sea breeze by locating aI-mag/ad, al-majlis and al-suffah (guests and living rooms) in the north and west parts of the house while reserving the southern and eastern parts for only almuakhir and service areas such as the stairway, latrines, storages and so on [13].

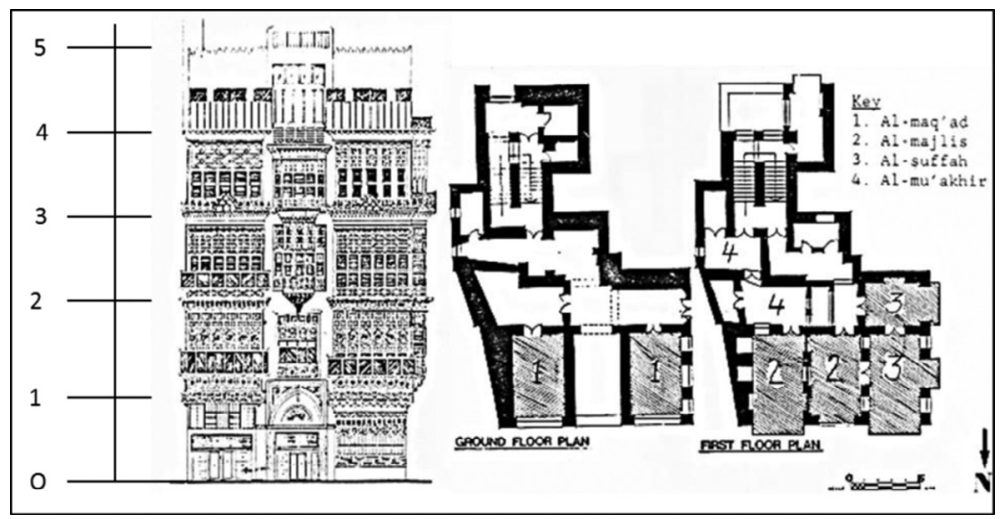

Figure 5: A traditional Hejazi house in historic Jeddah [13]. 
Another classic architectural response to climate is al-mabit built on the uppermost floor. This room was invariably constructed of panelled woodwork with movable louvres, and a light roof, in contrast with the massive lower floors. The latter would stay cool during the daytime in the summer but would tend to warm up in the late night. Al-mabit, on the other hand, would be warm during the daytime but would cool down quickly at night, when it could be used for sleeping [13] (Fig. 5).

\subsubsection{Materials used}

Stones, locally produced concrete and mud were the most commonly used materials in the construction of Hejaz buildings [11]. Public awareness of climate and its impacts on the buildings in the Hejaz region did not come by chance, but after long experiences of adaptation with the local weather. The features of absorption and heat insulation that are available in these materials led the old Hejazi builders to choose them to be the main materials for exterior facades (see Fig. 6).

In the interior spaces the main features of the traditional Hejaz buildings consisted of thick walls of up to $45-75 \mathrm{~cm}$. Thick walls were introduced as a countermeasure against the high solar temperature and trapped cooler temperature during the evenings. Gypsum and mud were used as a sealant in order to protect the walls from rain and dampness, especially the houses built in the hot-humid regions. In these times there were many varieties of materials available in order to achieve sufficient thermal resistance and insulating capacity such as concrete block walls, cavity walls and clay [3].

The traditional design of the Hejaz houses consisted of thick roofs made from stone rubble and earth supported by palm trees and timber beams. The roof contributed for most to the heat gain compared to other features of the Hejaz buildings. However, the roofs required a high level of maintenance in order to reduce the chance of leaks or collapse during heavy rainfalls (if founded) [11].

Traditionally basements were used as an extra living space, which were rare and found in the hot-dry climatic zone, mostly in Hejaz (Makkah and Al-Medina). In the terrain, which was sandy, it was difficult to build basements due to the lack of technology. However, the basements remained cool during the summer and remained warmer during the winter, which made it a valuable living space for families. After examining the traditional Hejaz house closely it became clear that thick stones, concrete and clay were used to preserve the cold in the summer and protect the building from intense heat during the day [3] (Fig. 7).

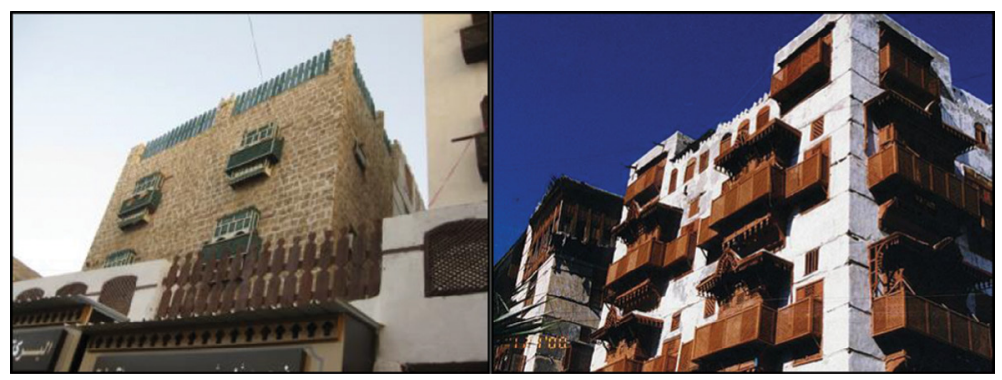

Figure 6: The materials that are used in the construction of Hejaz's buildings [7]. 




Figure 7: Three-dimensional section of a traditional Hejazi house [14].

\subsubsection{Rawashans and courtyards}

Rawashans and courtyards were constructed using traditional methods of air ventilation in the Hejaz regions as a main countermeasure for the build-up of intense heat. The courtyards were mainly found in the hot-dry climatic zone in Hejaz. On the other hand, rawashans were found in both hot-dry and hot-humid climatic zones and were preferred for privacy as well $[3,11]$. This section will illustrate the characteristics and designs of both rawashans and courtyards and their importance.

Firstly, rawashan (the closed wooden balcony, plural: rawashans) served Hejaz's inhabitants as a primary means for exhibiting wealth, prestige and status [15]. It also had functional and aesthetic roles. The functional roles were to create privacy that Hejaz's citizen needs, to let the light come through, to preserve the cool weather in summers and to control the circulation of air from outside to inside the buildings.

Rawashan also plays a significant role in terms of providing natural daylight and natural ventilation during the day and night-times [16]. However, the shapes and sizes of rawashans are different due to their location in the house, and the outer part of the rawashans is called mashrabyahs (see Fig. 8). Large rawashans, for instance, are usually located by the master bedroom or the living room because it's the room which is accommodated by most of the inhabitants during the day. Often the Hejaz inhabitants keep pottery on the mashrabyahs for cool water (drinking water), and this is further evident for the importance of rawashan in the process of ventilation and control of the ventilation system in general. It should also be mentioned that the ventilation of air was horizontally starting from the rawashan to the whole floor. 


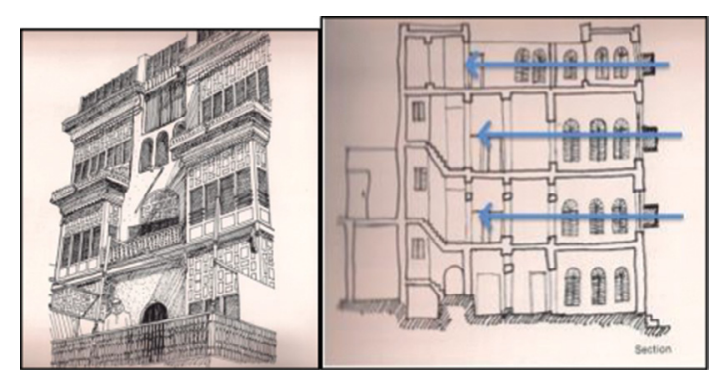

Figure 8: Rawashan and its roles [3].

Secondly, courtyards found in atrium adobe houses were preferred for maintaining ventilation in the hot-dry climatic zone. The courtyard was located in the core of the house to act as a climatic moderator and to create a prestigious open space [3]. Atrium adobe houses required necessary daylight and a constant airflow throughout the day in order to keep the building at a cool temperature. The main role of the courtyard was to create a climatic moderator during the hot-dry weather condition [15] .

The courtyard allows the cool night air to descend into the courtyard during the evening and surrounds each room with a cool breeze to lower the temperature (Fig. 9). During the daytime the sun's beams hit the floor of the courtyard resulting in cool air to rise and pass through the surrounding rooms. The thick walls in the buildings restrict the intense heat from penetrating into the house. Therefore, the courtyard floor and the interior of the house stay warm and allow the cool air to circulate throughout the house before being released during sunset.

The design of the courtyard relied on carefully planned measurements with correct width and depth so that the necessary dimensions were measured and the climatic moderation could be achieved. It was important that the width and depth were not too narrow or deep; otherwise the cool air released during the day would not be able to flow through the surrounding rooms efficiently. In the case of wrong dimensions the courtyard just acted as a ventilation shaft and just contained heat $[3,11,16]$.

\subsubsection{The irregular urban fabric}

The unique urban fabric (irregular fabric) in the old Arabic-Muslim cities allows interference of shade and shadow in different buildings, and that provided a natural air stream all day (Fig. 10) [17]. We can notice that most of the old cities have irregular systems that help them to adapt with the climate change [18]. The layout of the street also played a role in the interference of shade and shadow, depending on the number of houses along the narrow street the more congestion of houses the more need for wider spacing in order to allow better range of shade and air ventilation [1].

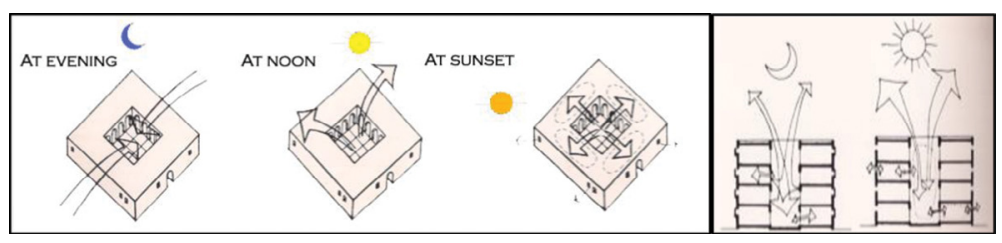

Figure 9: Ventilation in courtyards during daytime [3]. 


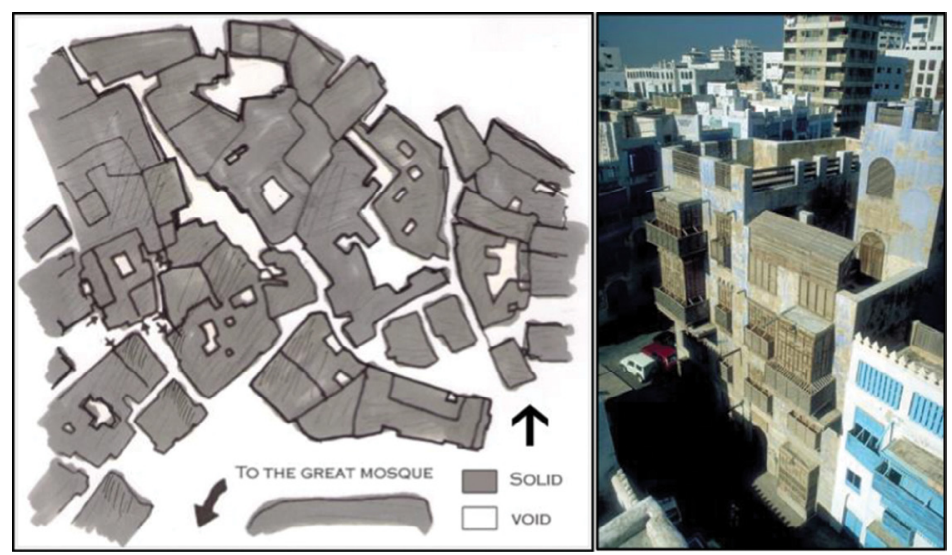

Figure 10: Map of the old Makkah city pattern shows the irregular arrangement of streets [9] and it also shows how the Hejazi settlements pattern could provide a comfortable shade [7].

The traditional closely knit building layout contributed to the cool temperature due to the shading from the compact building arrangements [19]. Aligning buildings close to each other along the east-west axis protects the buildings from the low sun during the afternoons. Buildings, which consisted of longer dimensions, were built facing the north and south, which is also known as solar orientation. These layouts of the streets were used as techniques of shading to avoid direct sunshine; various shapes and sizes of the buildings were designed to achieve this, such as square-or rectangular-shaped buildings, and long-dimensional buildings (see Fig.11).

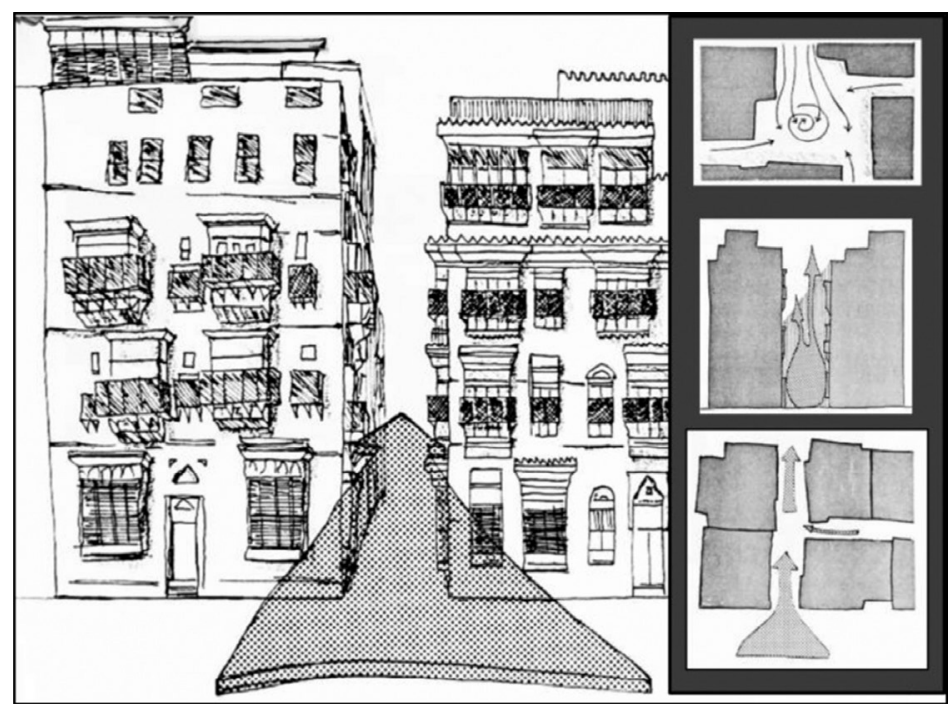

Figure 11: The mechanism used for providing breeze in Hejazi cities [13]. 


\section{CONCLUSION}

The paper begins with the introduction of the location and importance of the Hejazi region for Muslims worldwide. The region includes two different climatic zones, hot-dry and hothumid, which have had a considerable influence on the techniques used in the traditional design and layouts of streets and settlements. Different solutions have been founded in the traditional Hejazi architecture to adapt with the changing climate. For instance, courtyards and rawashans are common techniques used to improve air conditioning and air circulation in households. As a result, the common techniques have become a prestigious asset and root of Islamic architecture in traditional Hejazi architecture. Although traditional Hejazi architecture used imported materials and techniques influenced by a multicultural society, the Hejazi builders combined local knowledge with external influences in order to construct luxurious designs, which suit the Islamic and Hejazi community.

The author believes that the traditional architecture of the Hejaz region is an important part of the contemporary Saudi Arabian culture and vernacular architecture and it deserves to be re-evaluated, rediscovered and developed, rather than ignored for modern design. Its outstanding qualities can inspire new designs for contemporary construction. The traditional Hejaz architecture can be used as a benchmark to solve common problems regarding climate adaptability using environmental-friendly materials. They can either be adapted to today's requirements or converted to new uses. The transmission of this unique architectural heritage to future generations would be a valuable victory for Saudi Arabia's efforts in preserving its precious culture. Saudi Arabia being a champion for sustainable and traditional designs deserves that.

\section{REFERENCES}

[1] Olgyay, V., , Design with Climate, 4th ed. Princeton University Press: Princeton, NJ, 1973.

[2] Saudi Presidency of Meteorology and Environment Website: www.pme.gov.sa (accessed on April 2016)

[3] Kaizer, T., Shelter in Saudi Arabia, Academy Editions/st, Martins press, the USA, 1984

[4] Saudi Aramco Maps (2015), Saudi Major Cities Map, The Saudi archive in the Saudi American Petroleum Company, Riyadh, Saudi Arabia.

[5] Weart, R., The Discovery of Global Warming, revised, expanded edition, 2008.

[6] Vincent, P., Saudi Arabia: An Environmental Overview, Taylor \& Francis, 2008.

[7] Bagader, M. Investigation of How the Hejazi Architecture Responded to Climate Change during History until Contemporary Times: Jeddah's buildings as a Case Study, Unpublished Master thesis, University of Liverpool, UK 2010.

[8] Ragette, F., Traditional Domestic Architecture of The Arab Region, American University: Sharjah, 2003.

[9] Fadaan, Y., Traditional Houses of Makkah. King Faisal University: Dammam, 1983.

[10] Rapaport, A. House, Form and Culture, Prentice Hall: Upper Saddle River, NJ, 1969.

[11] Hariri, M., Housing in Central Makkah: The Influence of Hajj, Unpublished PhD thesis, Newcastle University, UK, 1986.

[12] Idea Center, Research Division, Paris: https://ideas.repec.org/ (accessed in February 2016).

[13] Al-Lyaly, S. The traditional house of Jeddah: a study of the interaction between climate, form and living patterns, Unpublished $\mathrm{PhD}$ thesis, The University of Edinburgh, UK, 1990. 
[14] Matthew, R. et al., Study of the Historical District of Jeddah, Jeddah: Ministry of Municipalities and Rural Affairs, Saudi Arabia, 1980.

[15] Petersen, A. Dictionary of Islamic Architecture, Routledge: London, 1996.

[16] Bagader, M. Investigation of How the Hejazi Architecture Responded to Climate Change during History until Contemporary Times: Jeddah's buildings as a Case Study, Unpublished Master thesis, University of Liverpool, UK 2010.

[17] Al-Hathloul, Saleh Urban Forms in Arab-Muslim Cities: Physical Elements or Themes and Principles, Alfaisal Architecture \& Planning Journal, King Fisal University Dammam, Saudi Arabia, first issue, 1980.

[18] Doxides Associates , Riyadh: Existing conditions, from: Islamic architecture and urbanism; selected paper in a symposium organized by the College of Architecture and Planning, King Faisal University, edited by Aydin Germen, 1971.

[19] Mortada, H., Traditional Islamic Principles of Built Environment, Routledge: London, 2003. 